\title{
Targeted Tandem Mass Spectrometry for High-Throughput Comparative Proteomics Employing NanoLC-FTICR MS with External Ion Dissociation
}

\author{
Hyuk Kang, Ljiljana Paša-Tolić, and Richard D. Smith \\ Biological Sciences Division, Pacific Northwest National Laboratory, Richland, Washington, USA
}

\begin{abstract}
Targeted tandem mass spectrometry (MS/MS) is an attractive proteomic approach that allows selective identification of peptides exhibiting abundance differences, e.g., between culture conditions and/or diseased states. Herein, we report on a targeted LC-MS/MS capability realized with a hybrid quadrupole-7 tesla Fourier transform ion cyclotron resonance (FTICR) mass spectrometer that provides data-dependent ion selection, accumulation, and dissociation external to the ICR trap, and a control software that directs intelligent MS/MS target selection based on LC elution time and $\mathrm{m} / \mathrm{z}$ ratio. We show that the continuous on-the-fly alignment of the LC elution time during the targeted LC-MS/MS experiment, combined with the high mass resolution of FTICR MS, is crucial for accurate selection of targets, whereas high mass measurement accuracy MS/MS data facilitate unambiguous peptide identifications. Identification of a subset of differentially abundant proteins from Shewanella oneidensis grown under suboxic versus aerobic conditions demonstrates the feasibility of such approach. (J Am Soc Mass Spectrom 2007, 18, 1332-1343) @ 2007 American Society for Mass Spectrometry
\end{abstract}

$\mathrm{L}$ iquid chromatography combined with tandem mass spectrometry (LC-MS/MS) is a widely used approach for the identification of peptides in proteomics applications. However, not all species in a given LC separation are amenable to MS/MS because of time constraints (i.e., a limited elution period for a peak). To circumvent this limitation, several experimental schemes have been developed, such as peak parking [1, 2], exclusion lists [3], and even multiplexed MS/MS [4]. Despite these efforts, many species remain unidentified with various precursor ion selection methods, particularly when low abundance species co-elute with high abundance species and when sample amounts are limited, making it unfeasible to repeat the experiment many times. However, in many proteomics studies, such as clinical studies when one is looking for significant differences between, e.g., healthy and diseased subjects, the goal is to gain insight into the differences in protein abundances among different conditions/states rather than obtaining a global snapshot of the proteome. An LC-MS/MS method that could target "interesting" species (e.g., differentially abundant peptides) for identification, would be particularly beneficial in this context.

Some commercial mass spectrometers offer a rudimentary targeted MS/MS capability, but a more ad-

Address reprint requests to Dr. Richard D. Smith, Pacific Northwest National Laboratory, 3335 Q Ave., K8-98, P.O. Box 999, Richland, WA 99352, USA. E-mail: dick.smith@pnl.gov vanced capability is not yet commercially available. For instance, Finnigan (San Jose, CA) linear ion trap based spectrometers (LTQ, LTQ-FT, LTQ-Orbitrap) allow targets to be selected based on the $m / z$ value. However, the elution times cannot be precisely specified, and alignment of the LC elution times between different LC-MS analyses cannot be performed, which is an increasingly important issue as LC flow rates are decreased to improve sensitivity [5].

We have recently demonstrated the feasibility of targeted MS/MS based on the abundance ratios (ARs) of ${ }^{14} \mathrm{~N} /{ }^{15} \mathrm{~N}$-labeled peptide pairs using an LC-FTICR platform [6]. In a tryptic peptide mixture of Shewanella oneidensis proteins, we were able to specifically target and identify species that were differentially abundant in suboxic versus aerobic conditions; for several identified proteins, differential abundance was confirmed by alternative techniques [7]. To realize this targeted MS/MS experiment, the sample was first analyzed in MS-only mode using an LC-FTICR system, and the ARs of all detected peptide pairs were calculated. The $\mathrm{m} / \mathrm{z}$ values and LC elution times for "interesting pairs", i.e., pairs showing differential abundance between the two isotopically labeled versions of the peptide, were consolidated into an "attention list." Next, an LC-MS/MS experiment was conducted in which the "attention list" directed the MS/MS acquisition to specific targets. In this initial demonstration, ion selection and dissociation were performed within the ICR trap, employing stored waveform inverse Fourier transform (SWIFT) [8] fol- 
lowed by sustained off-resonance irradiation collisioninduced dissociation (SORI CID) [9], and variations in peptide LC elution times were corrected using linear alignment based on two early-eluting species. Note that dissociation in the ICR trap requires a pulse of a neutral gas, which has to be pumped out before ion excitation/ detection, and is therefore incompatible with fast online LC-MS applications.

Herein, we report a targeted LC-MS/MS platform designed to improve efficiency and throughput for comparative proteomics by performing precursor ion selection (via RF/DC quadrupole) and dissociation (via tailored noise waveform, TNW-CID) [10] external to the ICR trap. In addition, we show that the continuous alignment of the targeted LC-MS/MS experiment with the reference LC-MS experiment, using multiple elution markers, is crucial for pin-pointing the targets in twodimensional (2D) $m / z$ versus LC elution time space.

\section{Experimental}

\section{Sample Preparation}

S. oneidensis MR-1 cells were cultured either aerobically on normal media $\left({ }^{14} \mathrm{~N}\right)$ or under suboxic conditions on isotopically-labeled media $\left({ }^{15} \mathrm{~N}\right)$ as described previously [6]. Cell lysis and tryptic digestion procedures are also described in the preceding publication [6]. Equal amounts of tryptic digests from suboxic and aerobic samples were combined and stored at $-80{ }^{\circ} \mathrm{C}$ until analyzed.

\section{NanoLC}

Peptide reversed phase liquid chromatography (RPLC) separations were performed using a system similar to that ${ }^{\circ}$ described $^{\circ}$ by $^{\circ}$ Shen $^{\circ}$ et $^{\circ}$ al. $.^{\circ}[11] .^{\circ}$ The $^{\circ}$ separation $^{\circ}$ was performed under constant pressure conditions at 10,000 psi, using two ISCO (Lincoln, NE) model 100 DM high-pressure syringe pumps. The column $(80 \mathrm{~cm} \times 50$ $\mu \mathrm{m})$ was packed in-house with Phenomenex (Torrance, CA) Jupiter particles (C18 stationary phase; $3-\mu \mathrm{m}$ particles; $300 \AA$ pore size). Mobile phase A consisted of $0.2 \%$ acetic acid, $0.05 \%$ trifluoroacetic acid (TFA), $99.75 \%$ water, and mobile phase $\mathrm{B}$ consisted of $0.1 \%$ TFA, 9.9\% water, and 90\% acetonitrile. Approximately 2 $\mu \mathrm{g}$ of peptides were loaded onto the column, and the gradient was started and ran from $100 \%$ A to $\sim 60 \%$ B in $180 \mathrm{~min}$; the initial flow rate through the column was $\sim 0.2 \mu \mathrm{L} / \mathrm{min}$. Electrospray ionization (ESI), using a chemically etched tip for stable and reproducible operation [12], 'was 'used to interface ${ }^{\circ}$ the ${ }^{\circ}$ RLC $^{\circ}$ separation to the mass spectrometer.

\section{FTICR MS}

The FTICR mass spectrometer used a 7 tesla superconducting magnet (Oxford, UK) and an in-house built ion beam ${ }^{\circ}$ instrument ${ }^{\circ}$ described $^{\circ}$ previously $^{\circ}[10],{ }^{\circ}$ with $^{\circ}{ }^{\circ}$ few recent modifications. Briefly, the mass spectrometer incorporates an ESI source (with the chemically etched tip $[12]),{ }^{\circ} a^{\circ}$ heated ${ }^{\circ}$ capillary $^{\circ}\left(160^{\circ} \mathrm{C}\right),{ }^{\circ}$ an ${ }^{\circ}$ electrodynamic

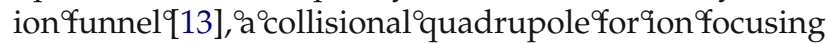
$\left(Q_{0}\right)$, two selection quadrupoles $\left(Q_{1}\right.$ and $\left.Q_{2}\right)$, an accumulation quadrupole $\left(\mathrm{Q}_{3}\right)$, and a transfer quadrupole $\left(\mathrm{Q}_{4}\right)^{\circ}$ that $^{\circ}$ leads ${ }^{\circ}$ to $^{\circ}$ an $^{\circ}$ open $^{\circ}$ cylindrical $^{\circ} \mathrm{ICR}^{\circ} \operatorname{trap}^{\circ}[14] .{ }^{\circ} \mathrm{Q}_{1}$ is an RF-only quadrupole with notch ejection capability, which offers "dynamic range expansion applied to mass $^{\circ}$ spectrometry" ${ }^{\circ}(\text { DREAMS })^{\circ}$ capability $^{\circ}\left[15,{ }^{\circ} 16\right]$, but was used only as an ion guide in this study. $Q_{2}$ is a commercial quadrupole mass filter $(6 \mathrm{~mm}$ rod diameter, Extrel) powered by a commercial RF power supply (150-QC, Extrel, Pittsburgh, PA) working at $880 \mathrm{kHz} . \mathrm{Q}_{2}$ has RF-only end sections (prefilter and postfilter) to reduce fringe field effect, thus increasing ion transmission at the entrance and the exit of the quadrupole. The $\mathrm{Q}_{2}$ power supply is controlled by two analog voltages and a trigger; "Mass Command" voltage controls the RF amplitude (i.e., the center of mass selection window); " $\Delta \mathrm{M}$ " voltage sets the resolution (i.e., the width of transmission window), and the trigger (TTL) turns on the quadrupolar DC (i.e., the mass resolving mode). $Q_{3}$ operates at $1.05 \mathrm{MHz}, 370 \mathrm{~V}_{p-p}$ and is enclosed within a collision cell to enable operation under elevated pressure during accumulation or CID. During ion accumulation (typically $150 \mathrm{~ms}$ ), the pressure in the $\mathrm{Q}_{3}$ region rises to $\sim 10^{-3}$ torr by $\mathrm{N}_{2}$ gas pulsed through a piezoelectric valve. We have confirmed that the gas pulse does not induce dissociation of peptides (e.g., phosphorylated angiotensin II) during accumulation when $\mathrm{Q}_{0}$ is biased at $8 \mathrm{~V}$ and $\mathrm{Q}_{3}$ is grounded; however, dissociation can be induced by biasing $\mathrm{Q}_{3}$ to below -10 $\mathrm{V}$, and becomes prominent at $-17 \mathrm{~V}$. After being accumulated in $Q_{3}$ for a specified period of time (e.g., $0.1 \mathrm{~s}$ for MS acquisition), the ions are transferred through $\mathrm{Q}_{4}\left(1.1 \mathrm{MHz}, 280 \mathrm{~V}_{p-p}\right)$ to a three-segment (each segment has a length-to-diameter ratio of 1 ), open cylindrical ICR trap for $m / z$ analysis.

In the MS/MS mode of operation, the precursor ion is selectively transmitted through $\mathrm{Q}_{2}$ and accumulated in $\mathrm{Q}_{3}$. Another gas pulse is injected and auxiliary broadband dipolar RF (TNW) is applied to $\mathrm{Q}_{3}$ to dissociate the accumulatedions 910$].{ }^{\circ}$ Alternatively, precursor ion could be dissociated employing resonant dipolar ${ }^{\circ} \mathrm{RF}^{\circ}[17],{ }^{\circ}$ or $^{\circ}$ lowering ${ }^{\circ}$ bias $^{\circ}$ of ${ }^{\circ}$ the ${ }^{\circ}$ accumulation quadrupole $^{\circ}\left[18,{ }^{\circ} 19\right],{ }^{\circ}$ or $^{\circ}$ even $^{\circ}$ by $^{\circ}$ applying $^{\circ}$ dipolar $^{\circ} \mathrm{DC}$ [20]. ${ }^{\circ}$ The $^{\circ}$ fragment ${ }^{\circ}$ ions ${ }^{\circ}$ are $^{\circ}$ subsequently ${ }^{\circ}$ transferred ${ }^{\circ}$ to the ICR trap for $m / z$ analysis.

Figure 1 shows the flow ${ }^{\circ}$ chart ${ }^{\circ}$ of the targeted MS /MS experiment. ${ }^{\circ}$ As ${ }^{\circ}$ in $^{\circ}$ our $^{\circ}$ previous $^{\circ}$ study $^{\circ}[6],{ }^{\circ}$ the ${ }^{\circ}$ targeted MS/MS experiment was controlled by two computers. Trapping voltages $\left(Q_{3}\right.$ and the ICR trap), triggers, and chirp excitation pulse were provided by a commercial data station (Odyssey; Finnigan FTMS). The transient signal was detected by a DAQ board (PCI-MIO-16E-1; National Instruments, Austin, TX) of an ancillary PC, and processed on-the-fly by in-house developed software $^{\circ}$ ICR-2LS ${ }^{\circ}$ (http:/ / ncrr.pnl.gov/software /); ${ }^{\circ} 128^{\circ} \mathrm{k}$ 


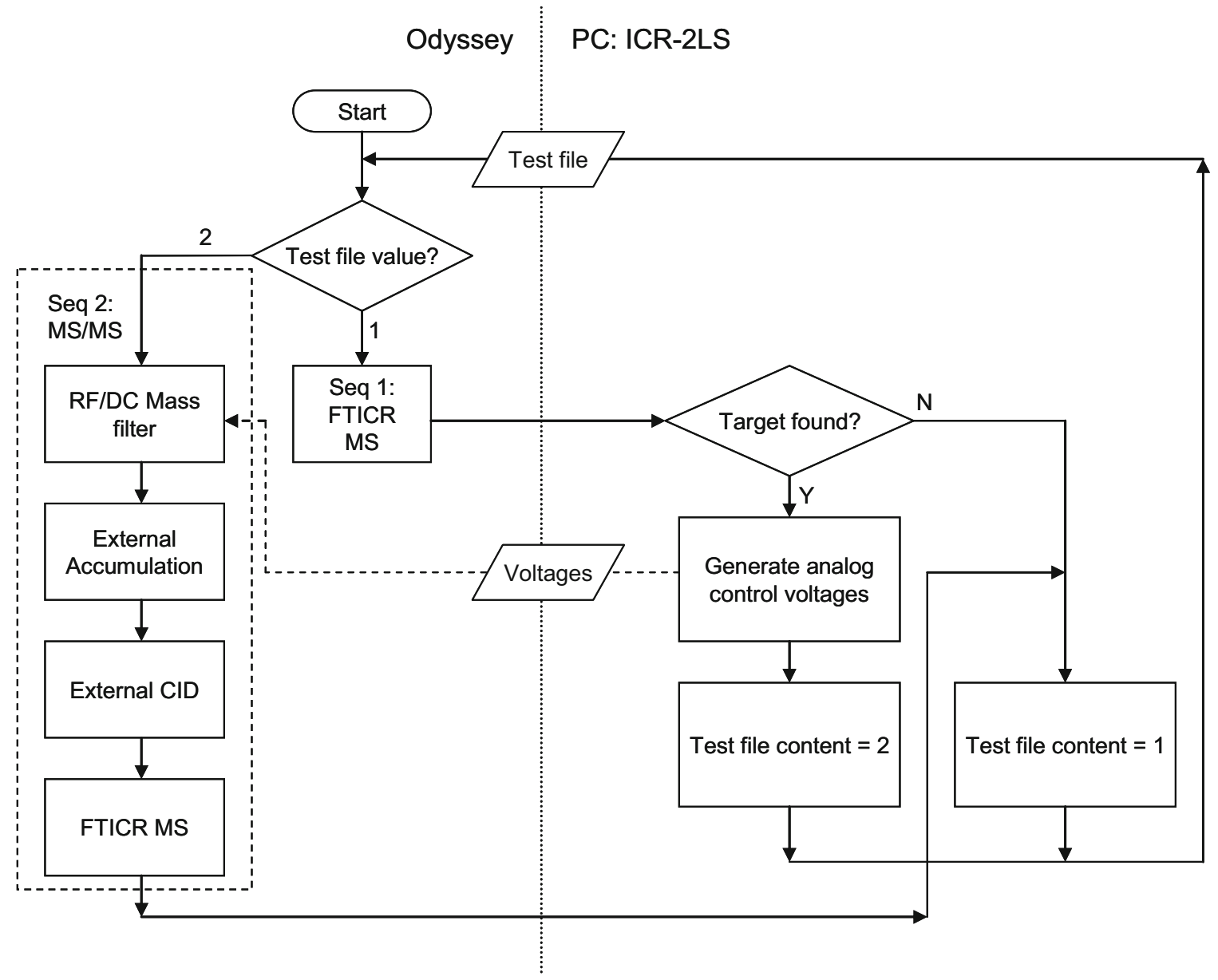

Figure 1. Experimental flow chart. Left hand side of the flow is executed by the Odyssey, and the right hand side by PC running ICR-2LS. Test file value of 1 specifies experimental sequence 1, i.e., MS acquisition, while test file value of 2 specifies experimental sequence 2, i.e., MS/MS acquisition.

points time domain signals were collected at $556 \mathrm{kHz}$ to reduce data-processing time.

To switch between MS and MS/MS modes, we used a Tcl/Tk script that runs the Odyssey controller program. The sequence (MS versus MS/MS) was specified in a text file, which was generated by ICR-2LS and located in a shared directory of the Odyssey controller computer. When a target is located in the MS acquisition, ICR-2LS calculates appropriate control voltages for $\mathrm{Q}_{2}$ to transmit the target ion, applies the voltage to the $\mathrm{Q}_{2}$ power supply through analog outputs of the DAQ board, and instructs the Odyssey controller to run an MS/MS sequence, which activates the RF/DC mass selection mode of $\mathrm{Q}_{2}$ operation during ion accumulation. After accumulation is complete, the Odyssey controller sends a trigger to apply $\mathrm{TNW}$ to $\mathrm{Q}_{3}$. TNW is generated by ICR-2LS before the experiment, stored in the ${ }^{\circ}$ memory ${ }^{\circ}$ of $^{\circ}$ an $^{\circ}$ arbitrary ${ }^{\circ}$ waveform ${ }^{\circ}$ generator ${ }^{\circ}$ board (PCI-5411, National Instruments) installed on the PC, and applied to $\mathrm{Q}_{3}$ when triggered by the controller. After MS/MS, ICR-2LS returns the mass spectrometer to MS mode of operation until the next target is found. Raw time-domain data are saved on the PC, and transferred to proteomics research information and storage ${ }^{\circ}$ management ${ }^{\circ}\left(\text { PRISM }^{\circ}\right)^{\circ}$ system $^{\circ}[21]^{\circ}$ at $^{\circ}$ the ${ }^{\circ}$ end $^{\circ}$ of the experiment for analysis and long-term storage.

\section{Attention List Generation}

We used ${ }^{14} \mathrm{~N} /{ }^{15} \mathrm{~N}$ metabolically labeled Shewanella oneidensis MR-1 cultures grown under aerobic and suboxic conditions to generate peptide ARs and choose MS/MS targets. A 1:1 mixture of tryptic digests of $S$. oneidensis grown aerobically $\left({ }^{14} \mathrm{~N}\right)$ and under suboxic conditions $\left({ }^{15} \mathrm{~N}\right)$ was analyzed by nanoLC-FTICR MS in triplicate. Raw data files were processed by ICR-2LS (running on a computer in the PRISM system) to generate $\mathrm{m} / \mathrm{z}$ values, ${ }^{\circ}$ abundances, ${ }^{\circ}$ and ${ }^{\circ}$ neutral ${ }^{\circ}$ masses $^{\circ}[22]$.

To determine ${ }^{14} \mathrm{~N} /{ }^{15} \mathrm{~N}$ peptide pairs we first assembled all measured neutral masses into "unique mass classe $^{\prime \prime \circ}\left(\mathrm{UMCs}^{\circ}[22]^{\circ} ;^{\circ} \mathrm{a}^{\circ} \mathrm{UMC}^{\circ}\right.$ is $^{\circ} \mathrm{a}^{\circ} \operatorname{set}^{\circ}$ of $^{\circ}$ points $^{\circ}$ in $^{\circ}$ the mass $^{\circ}$ versus $^{\circ}$ time $^{\circ}$ display $^{\circ}\left(\text { Figure }^{\circ} 2 a^{\circ}\right)^{\circ}$ that $^{\circ}$ corresponds $^{\circ}$ to the same chemical entity (i.e., the same peptide detected repeatedly as it elutes from the LC column). A UMC is defined by the median mass of its members, the sum of their abundances, and their spectrum range 


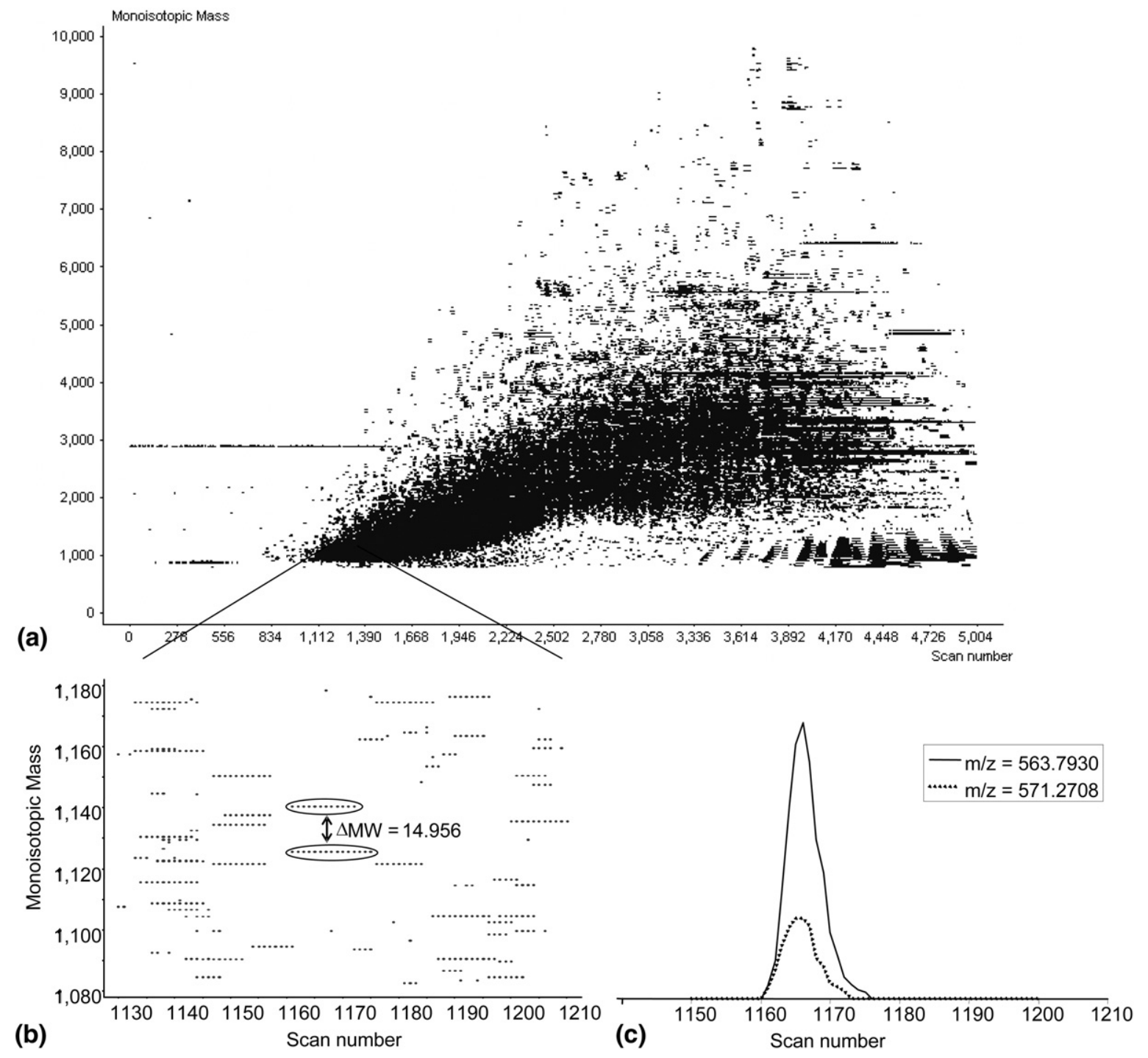

Figure 2. (a) 2-D display of the LC-FTICR analysis of 1:1 mixture of tryptic digests of S. oneidensis grown aerobically $\left({ }^{14} \mathrm{~N}\right)$ and under suboxic conditions $\left({ }^{15} \mathrm{~N}\right) ; 5000$ mass spectra were acquired in the course of $\sim 209 \mathrm{~min}$; each point corresponds to an isotopic distribution with coordinates specifying its

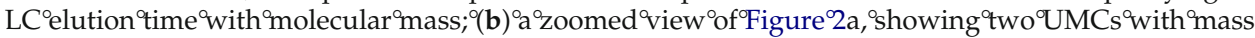
difference corresponding to 15 nitrogen atom substitution; (c) selected ion chromatograms of the two $\mathrm{UMCs}^{\circ} \operatorname{circled}^{\circ}$ in $^{\circ} \mathrm{Figure}^{\circ} 2 \mathrm{~b}^{\circ}$ indicates ${ }^{\circ}$ their ${ }^{\circ}$ elution ${ }^{\circ}$ time $^{\circ}$ overlap $^{\circ}$ and $^{\circ}$ abundance ${ }^{\circ}$ difference.

(equivalent to elution time window). This set of UMCs was then searched for pairs of peptides. To be identified as a pair, the mass difference between two UMCs had to be a unit mass multiple of the ${ }^{14} \mathrm{~N}-{ }^{15} \mathrm{~N}$ mass difference within a mass error tolerance of $0.02 \mathrm{Da}$, and their elution profile had to substantially overlap (i.e., the ${ }^{14} \mathrm{~N}$ and ${ }^{15} \mathrm{~N}$-labeled peptides largely co-elute). The ARs were then calculated for all ${ }^{14} \mathrm{~N} /{ }^{15} \mathrm{~N}$ peptide pairs as the sum of the ${ }^{14} \mathrm{~N}$ signal intensity to the sum of the ${ }^{15} \mathrm{~N}$ signal intensity. This $^{\circ}$ procedure ${ }^{\circ} s^{\circ}$ exemplified ${ }^{\circ}{ }^{\circ}$ Figure $2,{ }^{\circ}$ using $^{\circ}$ results $^{\circ}$ from $^{\circ} a^{\circ}$ particular $^{\circ}$ LC-MS $^{\circ}$ analysis ${ }^{\circ}$ as $^{\circ}$ a representative ${ }^{\circ}$ dataset. Figure $2 b^{\circ}$ shows ${ }^{\circ} a^{\circ}$ portion ${ }^{\circ}$ of the mass $^{\circ}$ versus $^{\circ}$ time $^{\circ}$ display $^{\circ}$ (Figure $\left.{ }^{\circ} 2 \mathrm{a}\right),{ }^{\circ}$ with $^{\circ}$ two $^{\circ} \mathrm{UMCs}$ circled; their mass difference of 14.956 indicates a content of 15 nitrogen atoms. Selected ion chromatograms of the two ${ }^{2} \mathrm{UCs}^{\circ}$ (Figure $2 \mathrm{c}$ ) ${ }^{\text {show }}{ }^{\circ}$ significant ${ }^{\circ}$ overlap in the elution profiles. An AR of 3.2 was calculated as the ratio of the UMC intensities.

Figure ${ }^{\circ} 3^{\circ}$ shows $^{\circ}$ the ${ }^{\circ}$ distribution ${ }^{\circ}$ of ${ }^{\circ} \log _{2}(\mathrm{AR})$ for the representative LC-MS dataset. Median (M) of the distribution is located at $\log _{2}(\mathrm{AR})=0.40$, with a standard deviation $(\sigma)$ of 1.08 . The median value corresponds to $\mathrm{AR}=1.3\left(=2^{0.40}\right)$, which is the actual mixing ratio of the two samples. Peptides with differential abundances between two growth conditions were then defined as UMC pairs with $\log _{2}(\mathrm{AR})$ outside $\mathrm{M} \pm \sigma$ range and used to generate a list of MS/MS targets. This procedure was repeated for each LC-MS dataset.

Replicate LC-MS datasets were aligned using the MSWARP $^{\circ}$ algorithm ${ }^{\circ}[23]^{\circ}$ yielding $^{\circ} 6718^{\circ} \mathrm{UMCs}^{\circ}$ (i.e., peptides) and 115 targets (i.e., peptide pairs with $\log _{2}(\mathrm{AR})$ outside the $\mathrm{M} \pm \sigma$ range) common among the 


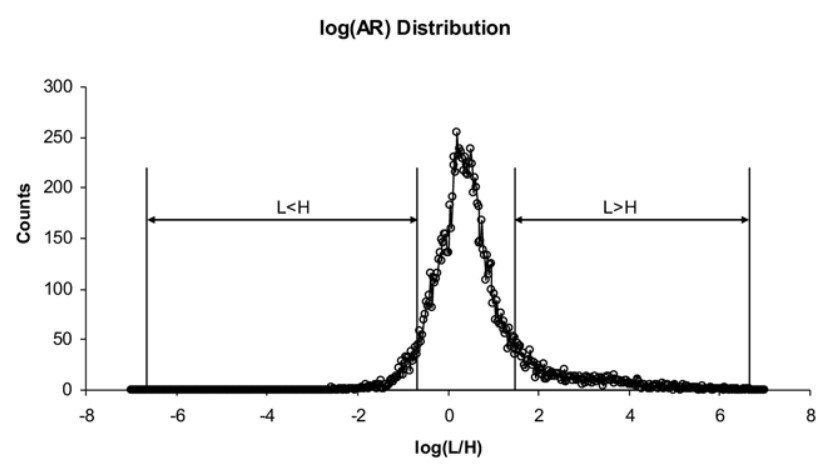

Figure 3. Distribution of $\log _{2}(\mathrm{AR}) . \mathrm{L}<\mathrm{H}$ identifies the range of ARs where ${ }^{14} \mathrm{~N}$ (light) peptides are significantly lower in abundance than ${ }^{15} \mathrm{~N}$ (heavy) peptides, i.e., $\log _{2}(\mathrm{AR})<\mathrm{M}-\sigma$, and vice versa.

three LC-MS datasets. These common targets were then used to create an attention list using the $\mathrm{m} / \mathrm{z}$ value and LC elution time associated with the more abundant member of the ${ }^{14} \mathrm{~N} /{ }^{15} \mathrm{~N}$ pair. The tolerance for $\mathrm{m} / \mathrm{z}$ was set at $25 \mathrm{ppm}$ to account for uncorrected space charge induced errors during LC-MS operation without automatic gain control and relatively short time-domains (128 $\mathrm{k}$ points). The drift of the measured mass due to the varying ion population during elution of a peptide is well $^{\circ}$ exemplified ${ }^{\circ}$ in $^{\circ} \mathrm{a}^{\circ}$ recent $^{\circ}$ publication ${ }^{\circ}[24]^{\circ}{ }^{\circ}$ Elution time tolerance was set at $3 \%$ to account for residual variation of the elution time.

\section{Results and Discussion}

In an effort to enhance the effectiveness of our previously ${ }^{\circ}$ reported ${ }^{\circ}$ targeted ${ }^{\circ} \mathrm{MS} / \mathrm{MS}^{\circ}$ method $^{\circ}[6]^{\circ}{ }^{\circ}$ we ${ }^{\circ}$ moved the precursor selection and the CID step external to the ICR trap to improve the duty cycle and applied an improved LC elution time correction algorithm to increase target selection specificity.

\section{RF/DC Selection}

While $\mathrm{Q}_{2}$ was operated in RF-only mode during MS acquisition to allow broadband transmission, the $\mathrm{RF} / \mathrm{DC}$ mass filtering mode was used during MS/MS acquisition to selectively transmit the precursor ion to $\mathrm{Q}_{3}{ }^{\circ}$ Figure ${ }^{\circ} 4 a^{\circ}$ shows ${ }^{\circ}$ the ${ }^{\circ}$ natural ${ }^{\circ}$ isotopic ${ }^{\circ}$ distribution ${ }^{\circ}$ of a doubly charged rennin inhibitor. By increasing $Q_{2}$ $\mathrm{RF} / \mathrm{DC}$ resolution, it was possible to isolate virtually a single ${ }^{\circ}$ isotopic $^{\circ}$ peak $^{\circ}$ at $^{\circ} \mathrm{m} / \mathrm{z}={ }^{\circ} 513.282^{\circ}$ (Figure $^{\circ} 4 \mathrm{~b}$ ). However, as the transmission efficiency of a quadrupole mass filter significantly decreases at high mass resolution ${ }^{\circ}[25]^{\circ}$ (e.g., ${ }^{\circ}$ to $^{\circ} \sim 0.1 \%^{\circ}$ of $^{\circ}$ broadband ${ }^{\circ}$ transmission in this case), it is unattractive for on-line LCMS/MS applications. That is, higher precursor ion intensity is desirable for producing high quality MS/MS spectra and more confident peptide identification. Additionally, the transmission window needs to be at least a few Da wide to preserve isotopic envelope and ensure correct monoisotopic mass determination [26].$^{\circ}$ To $^{\circ}$ achieve $^{\circ}$ high $^{\circ}$ enough $^{\circ}$ precursor $^{\circ}$ abundance $^{\circ}$ at acceptable $\mathrm{m} / \mathrm{z}$ selection window, the ion accumulation time for MS/MS acquisition was increased to $1 \mathrm{~s}$ and $\mathrm{RF} / \mathrm{DC}$ resolution was calibrated as follows. The transmission window of $Q_{2}$ was set to transmit $\Delta \mathrm{m} / \mathrm{z}$ of $\sim 3$ at $\mathrm{m} / \mathrm{z}=500$ to ensure transmittance of the entire isotopic envelope. Since $Q_{2}$ transmission efficiency drops significantly with increased $\mathrm{m} / \mathrm{z}$, we chose to increase selection window at high $\mathrm{m} / \mathrm{z}$ and maintain the overall transmission efficiency at $\sim 10 \%$ of broadband transmission. At $m / z=800$, the $\Delta m / z$ window was $\sim 30$. Thus, because of the high complexity of the peptide mixture, in many instances it will not be possible to isolate a single precursor ion before accumulation and CID; however, accurate mass measurements can facilitate such $^{\circ}$ multiplexed ${ }^{\circ} \mathrm{MS} \mathrm{MS}^{\circ}$ measurements ${ }^{\circ}[4]$.

In the SWIFT-SORI CID approach employed in our initial ${ }^{\circ}$ targeted ${ }^{\circ} \mathrm{MS} / \mathrm{MS}^{\circ}$ study $^{\circ}[6],{ }^{\circ} a^{\circ}$ precursor $^{\circ}$ ion $^{\circ}$ was accumulated in the external quadrupole together with other co-eluting ions, then transferred to the ICR cell and isolated by ejecting all of the remaining (i.e., unwanted) ions using SWIFT. While SWIFT isolation offers much higher resolution, RF/DC selection enables the accumulation trap to be filled predominantly with the ions of interest. For the low abundance precursor ions, enrichment simply by increasing ion accumulation time is usually impractical because of ion suppression, which typically tends to decrease the intensity of the

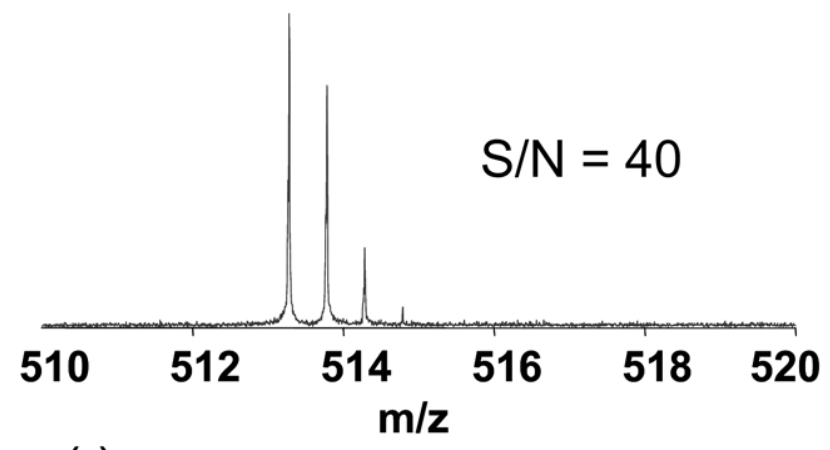

(a)

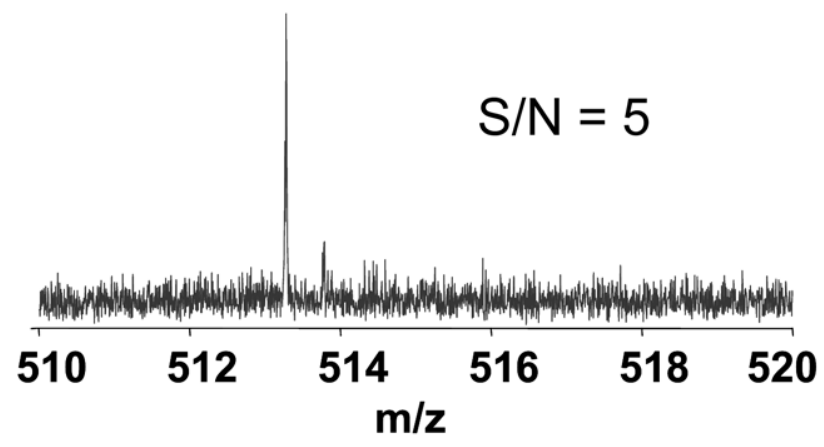

(b)

Figure 4. (a) Natural isotopic distribution of rennin inhibitor was detected when the RF/DC quadrupole $\left(\mathrm{Q}_{2}\right)$ was operated in RF-only mode during the MS acquisition. (b) Single isotope of rennin inhibitor was detected when $Q_{2}$ was switched to the high-resolution $\mathrm{rf} / \mathrm{DC}$ selection mode of operation. 
precursor ions with increased accumulation time. External selective accumulation effectively alleviates this problem by eliminating all but the ions of interest before the accumulation event and is therefore expected to improve overall MS/MS efficiency.

\section{TNW}

The precursor ion was selectively transmitted through $\mathrm{Q}_{2}$ and accumulated in $\mathrm{Q}_{3}$, and a gas pulse was used to assist accumulation and enable CID as described above. The ion was excited by TNW, which contains RF frequencies that range from 20 to $200 \mathrm{kHz}$ and correspond to secular frequencies of ions with $315 \leq m / z \leq$ 2620. Because higher $m / z$ ions are harder to break, TNW was generated to increase amplitude linearly with increasing ${ }^{\circ} \mathrm{m} / z$ [27], ${ }^{\circ}$ in $^{\circ}$ contrast $^{\circ}$ to $^{\circ}$ the $^{\circ}$ linear ${ }^{\circ}$ amplitudefrequency relation used in the original TNW-CID report [10]..$^{\circ}$ In $^{\circ}$ the $^{\circ}$ present $^{\circ}$ targeted $^{\circ}$ MS $/ \mathrm{MS}^{\circ}{ }^{\circ}$ overall ${ }^{\circ} \mathrm{TNW}$ amplitude was adjusted to $0.7 \mathrm{~V}$ to provide maximum fragment signal intensity for a wide range of precursors. Although TNW is a fixed data-independent waveform, data-dependent mass selection before CID coupled with high-resolution and mass measurement accuracy (MMA) offered by FTICR provides the true MS/MS capability. In addition, TNW offers the advantage of inherent $\mathrm{MS}^{n \geq 3}$ capability, since nascent fragment ions can be further dissociated. Further fragmentation could be particularly useful when the major fragmentation path is neutral loss (e.g., phosphopeptides).

\section{On-the-Fly Alignment}

The need for increased sensitivity in proteomic applications is virtually open-ended. Since ESI sensitivity increases as liquid flow rate to the ion source decreases, reducing the column i.d. is the most efficient way to improve sensitivity without sacrificing the separation quality ${ }^{\circ}[11] .{ }^{\circ}$ However, ${ }^{\circ} s^{\circ}$ the ${ }^{\circ}$ capillary ${ }^{\circ} . d .^{\circ}$ gets $^{\circ}$ smaller, the LC operation becomes less robust and more vulnerable to small changes in conditions (e.g., impurities can drastically change the flow rate and inevitably affect elution ${ }^{\circ}$ times $^{\circ}$ of $^{\circ}$ the ${ }^{\circ}$ analytes). ${ }^{\circ}$ Consequently, ${ }^{\circ}$ the ${ }^{\circ} \mathrm{LC}$ elution time alignment becomes increasingly important in an experiment linking multiple LC separations, such as targeted MS/MS analysis described in this report. Furthermore, targeted MS/MS experiment requires onthe-fly LC elution time alignment between the current and the reference LC-MS analysis. To this end, a twopoint linear correction was used to account for LC elution time variation in the initial targeted MS/MS report 96]. In the ${ }^{\circ}$ urrent ${ }^{\circ}$ study, 'we further'improved the on-the-fly alignment employing multiple elution markers and least-square linear regression. The elution markers needed to be unique within $\mathrm{m} / \mathrm{z}$ versus elution time space and intense enough to ensure repeated detection. UMCs that satisfied these criteria and were repeatedly detected in triplicate analyses were selected as candidate elution markers. Since the target is defined by its $m / z$ value (and not by molecular mass), each candidate marker $m / z$ value was compared with all $\mathrm{m} / \mathrm{z}$ values that could be generated from all detected UMCs (including all isotopic peaks with zero to four ${ }^{13} \mathrm{C}$ isotopes from all observed charge states). Candidate markers that could not be uniquely defined within 25 ppm $\mathrm{m} / \mathrm{z}$ and $20 \%$ LC elution time tolerances were discarded, which left only 61 confident LC elution time markers for this particular dataset. While two earlyeluting markers could be used for linear correction as introduced in the initial implementation, inclusion of these markers resulted in a large error for late-eluting species. Therefore, all unique markers were compiled into an elution marker list (which is different from the attention list) comprised of $\mathrm{m} / \mathrm{z}, \mathrm{m} / \mathrm{z}$ tolerance (25 ppm), elution time, elution time tolerance $(20 \%)$, and intensity threshold for each elution marker. Note that a significantly wider elution time tolerance was used for markers than for targets to correct for (possibly) large runto-run variations. To compensate for this increased uncertainty, we introduced intensity threshold (set at $25 \%$ intensity of the reference LC-MS dataset shown in Figure $\left.{ }^{\circ}\right)^{\circ}$ as $^{\circ}$ another ${ }^{\circ}$ dimension.

The peak list derived on-the-fly from each acquired spectrum was first compared with the elution marker list to correct for the elution time variation, and then with the attention list to determine whether the target was eluting. A least-squares fit of the original and current LC elution time values was used to calculate the slope and the intercept. If the calculated slope was within a specified range (set between 0.9 and 1.1), then new elution times of the targets were calculated and applied ${ }^{\circ}$ to $^{\circ}$ the ${ }^{\circ}$ attention ${ }^{\circ}$ list. ${ }^{\circ}$ Figure ${ }^{\circ} 5^{\circ}$ shows ${ }^{\circ}$ the ${ }^{\circ}$ plot $^{\circ}$ of observed elution time versus expected elution time for 17 markers that were found during a particular targeted MS/MS analysis. Note that even though unique markers (within $25 \mathrm{ppm} \mathrm{m} / \mathrm{z}$ and $20 \%$ elution time) were used, two points clearly deviated from the linear behavior (i.e., markers were misidentified). However, overall correction was still successful because these outliers were discarded since their produced slopes fell out of the specified range.

Figure $^{\circ} 6 \mathrm{a}^{\circ}$ shows $^{\circ} \mathrm{a}^{\circ}$ portion ${ }^{\circ}$ of ${ }^{\circ}$ the ${ }^{\circ}$ total $^{\circ}$ ion ${ }^{\circ}$ chromatograms (TIC) of the reference LC-MS and the MS part of a targeted LC-MS/MS analysis. To assess the effectiveness of the on-the-fly alignment, the elution time of the targeted MS/MS was reconstructed to match the elution time of the reference LC-MS employing the coefficients that were used for on-the-fly alignment. The reconstructed ${ }^{\circ I C}{ }^{\circ}$ is ${ }^{\circ}$ shown ${ }^{\circ}{ }^{\circ}{ }^{\circ}$ igures ${ }^{\circ} 6 \mathrm{~b}$, together ${ }^{\circ}$ with the reference TIC. Note that on-the-fly elution time alignment successfully corrected for a $47 \mathrm{~s}$ deviation at 5600 s, i.e., $\sim 1 \%$ elution time error.

\section{Targeted NanoLC-MS/MS}

The target peptides were compiled into the attention list and their elution times were continually updated using the on-the-fly alignment procedure described above. 


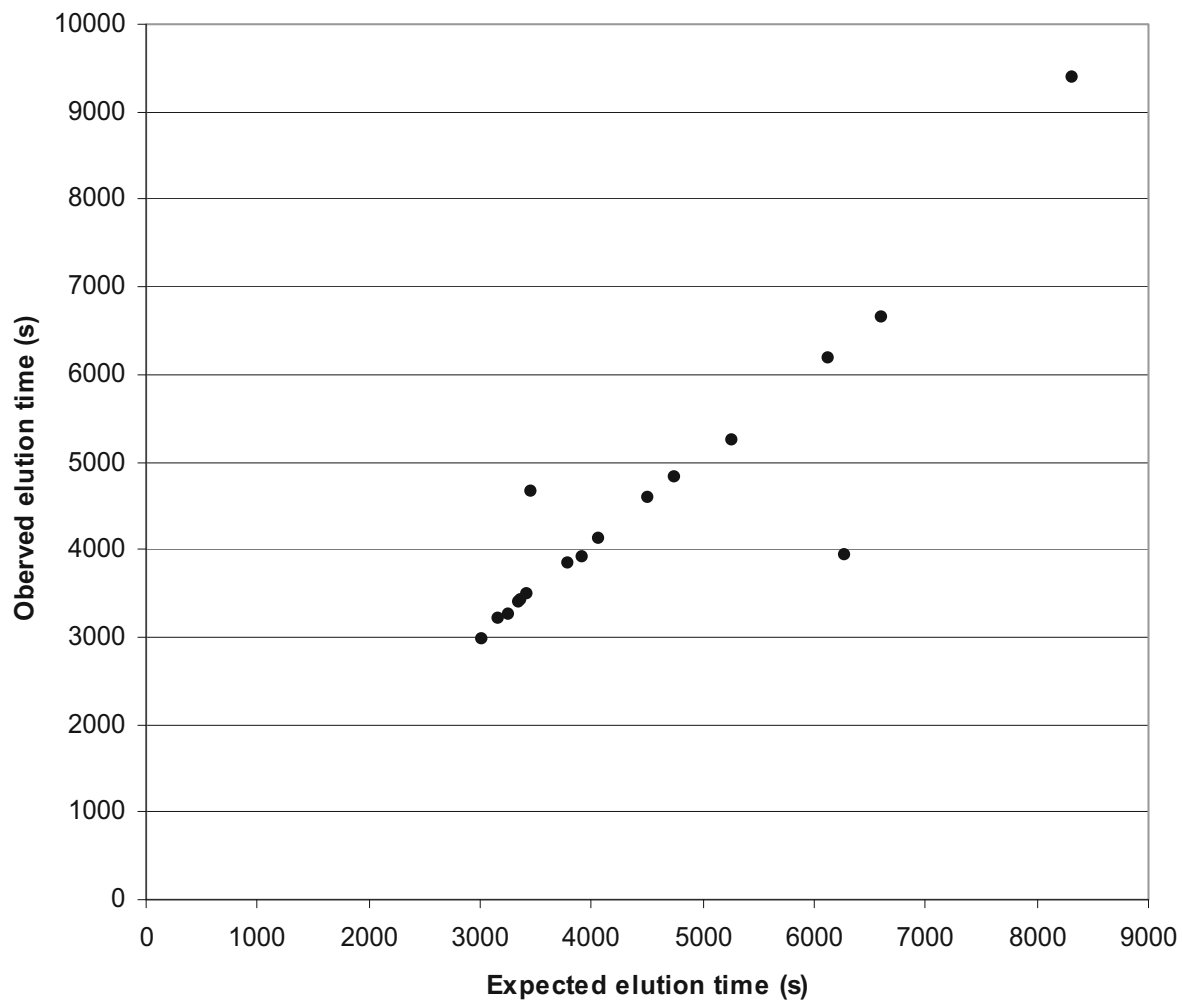

Figure 5. Correlation between the observed and expected LC elution time in a targeted LC-MS/MS analysis.

Whenever a target was found in the initial MS, its $\mathrm{m} / \mathrm{z}$ value was recorded in a log file and the ion was slated for MS/MS in the next acquisition. Since the attention list specifies only $\mathrm{m} / \mathrm{z}$ value corresponding to the target's most abundant isotope, the MS/MS spectra are acquired for ions that have $\mathrm{m} / \mathrm{z}$ similar to that of the target, but have a different neutral mass (i.e., different charge state). Such incorrectly selected targets were later removed from the logged $\mathrm{m} / \mathrm{z}$ values and not considered in subsequent analysis. This erroneous selection could be avoided by targeting neutral masses instead of $m / z$, but calculating neutral masses from mass spectra is slow and, at present, incompatible with on-line LC-MS/MS analysis. Alternatively, isotopic patterns (i.e., $\mathrm{m} / \mathrm{z}$ domain peaks) of each target can be generated and used as additional selection criteria during targeted LC-MS/MS analysis.

From targeted MS/MS analyses performed in triplicate, a total of 94 peptides out of 115 targets were correctly found and subjected to MS/MS in replicate analyses (51, 82, and 85, respectively). Eleven targets were not subjected to MS/MS because they eluted together with more abundant targets (i.e., in the current implementation, only the most abundant target is dissociated when multiple targets co-elute).

To identify peptides chosen for dissociation, precursor and fragment masses were searched against the $S$. oneidensis sequence database using the procedure described in ${ }^{\circ}$ detail ${ }^{\circ}$ previously $[4]^{\circ}$ and ${ }^{\circ}$ the ${ }^{\circ}$ following ${ }^{\circ}$ search parameters: the precursor was required to be a fully tryptic peptide; $10 \mathrm{ppm}$ mass tolerance for precursor; 25 ppm mass tolerance for fragments; minimum of 6 fragments required $(a, b$, or $y$ type ions and their respective $\mathrm{NH}_{3}$ and $\mathrm{H}_{2} \mathrm{O}$ loss fragments were considered); and modifications were not considered. Limited mass resolution and accuracy in MS/MS acquisition relate to short transients (needed to reduce on-the fly processing time) and lack of the automated-gaincapability (needed to control the total number of ions within the ICR cell, i.e., space charge effects). Note, however, that MMA for MS acquisition could be further improved ${ }^{\circ}$ using $^{\circ}$ multidimensional $^{\circ}$ recalibration $^{\circ}[28]$. Nevertheless, the parameters used herein correspond to Mascot ${ }^{\circ}[29]^{\circ}$ scores ${ }^{\circ}$ that ${ }^{\circ}$ fall ${ }^{\circ}$ above ${ }^{\circ}$ the homology ${ }^{\circ}$ threshold, and generally above identity threshold (see example below). To identify peptides derived from ${ }^{15} \mathrm{~N}$ labeled growth, the MS/MS search was repeated, but with the $S$. oneidensis sequence database recalculated using ${ }^{15} \mathrm{~N}$ isotope. As the more abundant member of the ${ }^{14} \mathrm{~N} /{ }^{15} \mathrm{~N}$ pair was listed in the attention list, the AR of the identified peptide was checked to confirm it had higher abundance than the other member of the pair, and peptide identity was further confirmed by the mass difference between the members of the pair, which corresponds to the number of nitrogen atoms.

An example of a targeted MS/MS spectrum is shown in Figure $7^{\circ} .{ }^{\circ}{ }^{\circ}$ target ${ }^{\circ}$ with $^{\circ} \mathrm{m} / z={ }^{\circ} 563.793^{\circ}$ and $^{\circ} \mathrm{t}^{\circ}=2930^{\circ} \mathrm{s}$, corresponding to the lighter member of the pair shown in $^{\circ}$ Figure ${ }^{\circ} 2{ }^{\circ}$ was $^{\circ}$ specified $^{\circ}$ in $^{\circ}$ the ${ }^{\circ}$ attention ${ }^{\circ}$ list. ${ }^{\circ}$ During the targeted MS/MS experiment, a peptide ion with $\mathrm{m} / \mathrm{z}$ 


\section{Before alignment}
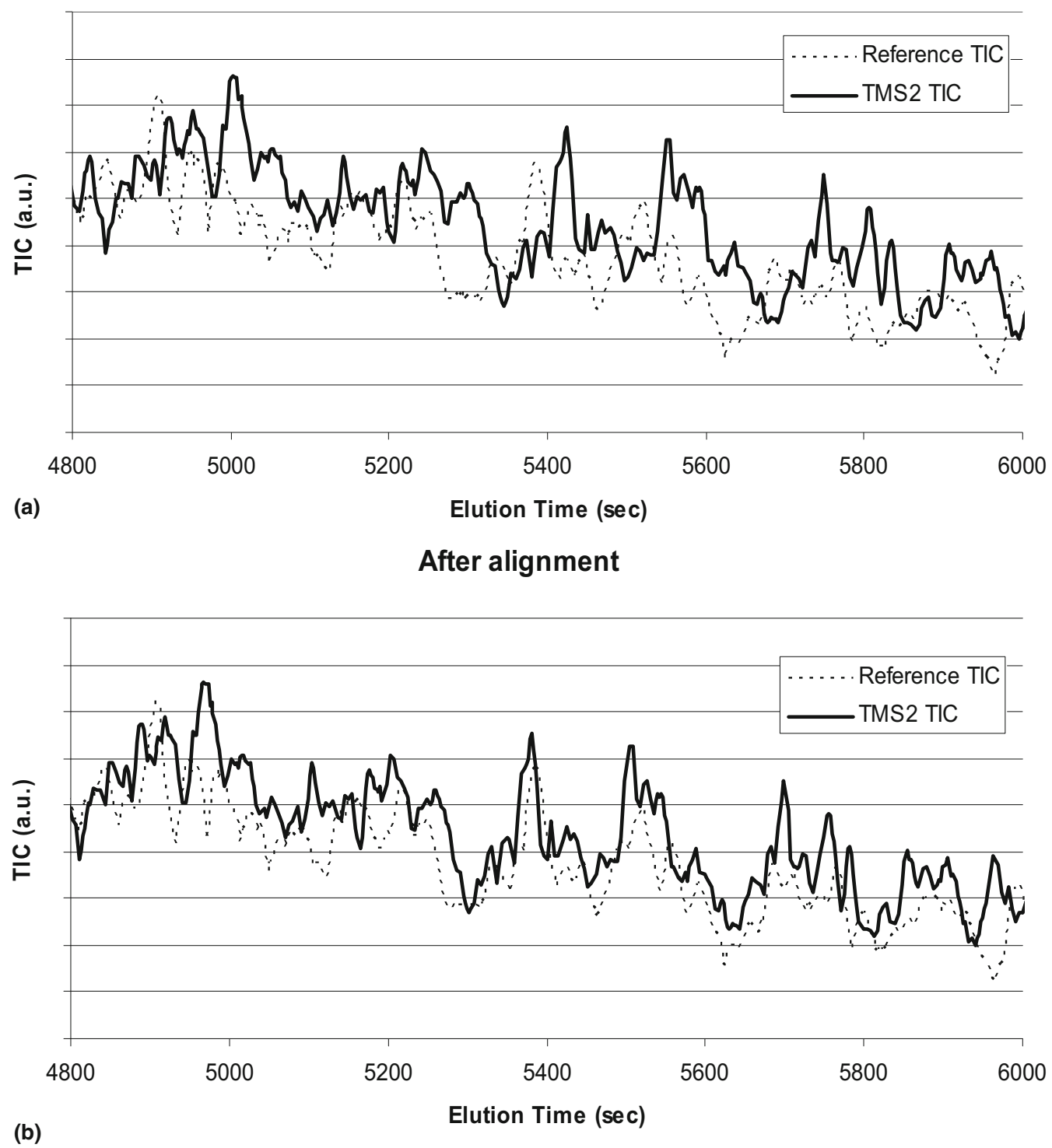

Figure 6. A portion of observed TICs of the reference LC-MS and the targeted LC-MS/MS analyses before (a) and after (b) LC elution time alignment.

$=563.799(\mathrm{MW}=1125.584)$ eluted from 2944 to $2985 \mathrm{~s}$; the MS/MS spectrum acquired at $2948 \mathrm{~s}$ uniquely identified this peptide as DAEKHLTNAK derived from SO3765 (PspA/IM30 family protein, transcriptional effector ${ }^{\circ}[30]^{\circ}{ }^{\circ}$ with $^{\circ} a^{\circ}$ root-mean-square ${ }^{\circ}$ fragment ${ }^{\circ} \mathrm{MMA}^{\circ}$ of $1.7^{\circ} \mathrm{ppm}^{\circ}$ (see Table 1$)$. The ${ }^{\circ}$ same ${ }^{\circ}$ spectrum ${ }^{\circ}$ was ${ }^{\circ}$ analyzed with Mascot with $10 \mathrm{ppm}$ tolerance for the precursor and $0.05 \mathrm{Da}(25 \mathrm{ppm}$ for a maximum $\mathrm{m} / \mathrm{z}$ of 2000) for fragments, with the sequence database limited to $S$. oneidensis. Mascot search yielded only one match corresponding to the same peptide DAEKHLTNAK with a score of 28 and an identity threshold of 15 for the search. It is worth noting that the less abundant ${ }^{15} \mathrm{~N}$ counterpart of this peptide was found separated by $14.947 \mathrm{Da}\left(\right.$ at $m / z=571.2728$ and $\mathrm{M}_{\mathrm{r}}=1140.531$ ), revealing the presence of 15 nitrogen atoms and thus confirming peptide identity $\left(\mathrm{C}_{47} \mathrm{H}_{79} \mathrm{~N}_{15} \mathrm{O}_{17}\right){ }^{\circ}$ Table $^{\circ} 2$ summarizes the peptides and proteins identified by triplicate targeted MS/MS analyses. The ${ }^{14} \mathrm{~N}$-labeled peptides $^{\circ}\left(\text { Table }^{\circ} 2\right)^{\circ}$ were $^{\circ}$ more $^{\circ}$ abundant $^{\circ}$ for ${ }^{\circ}$ aerobic growth and are therefore likely to be involved in aerobic ${ }^{\circ}$ respiration, ${ }^{\text {w }}$ while ${ }^{\circ}$ the ${ }^{015} \mathrm{~N}$-labeled ${ }^{\circ}$ peptides $^{\circ}\left(\mathrm{Ta}^{\circ}\right.$ ble $\left.^{\circ} 2\right)^{\circ}$ showed $^{\circ}$ higher $^{\circ}$ abundance ${ }^{\circ}$ for ${ }^{\circ}$ suboxic ${ }^{\circ}$ growth and are likely to be associated with anaerobic processes. A separate study, using a different experimental approach based on label-free quantitation and AMT tag proteomics, confirmed the increase in the abundance of the protein SO1484 and SO3765 under aerobic conditions, and the decrease in the abundance of the proteins SO0970, ${ }^{\circ} \mathrm{SO} 1777,{ }^{\circ} \mathrm{SO} 1778,{ }^{\circ} \mathrm{SO} 2361$, ${ }^{\circ}$ and $^{\circ} \mathrm{SO} 4410^{\circ}[31]^{\circ} .^{\circ} \mathrm{As}$ expected, the AMT-tag based study identified a larger set of differentially abundant proteins, since it relied on 
(a)

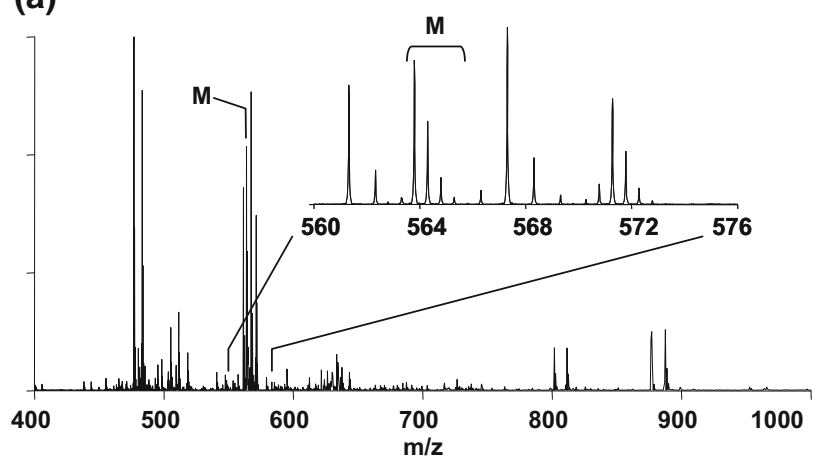

(b)

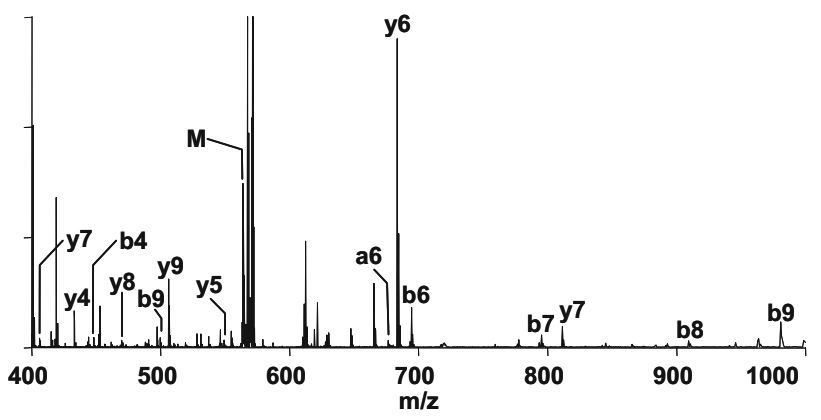

Figure 7. An exemplar targeted LC-MS/MS acquisition, taken at 2948 s. (a) FTICR mass spectrum of the precursor $(\mathrm{m} / \mathrm{z}=563.799)$, denoted as M. The inset shows a zoomed view in the $\mathrm{m} / \mathrm{z}$ region of the precursor. (b) Corresponding MS/MS acquisition with fragments labeled based on the database search.

AMT tag database derived from multiple LC-MS/MS analyses of heavily fractionated samples. However, the targeted MS/MS approach revealed several previously unidentified differentially abundant proteins. The AMT tag-based approach also considered peptides detected in one culture condition ("one-state" peptides), while this work considered only peptides identified in both culture condition ("two-state" peptides). While this constraint significantly limited the number of species identified in this demonstration, the "one-state" peptides could be easily incorporated into the attention list to facilitate identification of species showing large differences in abundance (i.e., "one-state" peptides).

Our experience thus far indicates the need for better online alignment of target lists to allow for improved selection of targets (and selection of more targets) based on more accurate $\mathrm{m} / \mathrm{z}$, neutral mass, and elution time information; efforts aimed at developing such an advanced targeted MS/MS capability are underway. Since on-line LC elution time alignment is of particular importance for targeted MS/MS experiments, the realtime alignment scheme will be advanced by employing $a^{\circ}$ variation ${ }^{\circ}$ of $^{\circ}$ the ${ }^{\circ}$ nonlinear ${ }^{\circ}$ warping ${ }^{\circ}$ algorithm ${ }^{\circ}[23]$, as well as LC approaches that reduce such variation. The elution time- $m / z$ pattern of an on-going LC-MS will be compared to that of a previously done LC-MS, and elution time of targeted species will be continuously updated. This capability will enable targeting molecular mass (instead of $\mathrm{m} / \mathrm{z}$ ) by specifying an isotopic envelope $(\mathrm{m} / \mathrm{z}$ pattern) instead of a single $\mathrm{m} / \mathrm{z}$ value.

In this study, acquisition was limited to $128 \mathrm{k}$ data points due to the processing time constraint; hence, current targeted MS/MS implementation suffers from limited mass resolution and accuracy. Efforts are aimed at shortening the overall processing time (e.g., FFT, peak picking, comparison with the attention list entries) to facilitate higher resolution and accuracy without sacrificing duty cycle.

Implementation of an electron capture dissociation (ECD) ${ }^{\circ}[32-34]^{\circ}{ }^{\circ}$ apability ${ }^{\circ} s^{\circ}$ expected ${ }^{\circ}$ to ${ }^{\circ}$ improve ${ }^{\circ}$ overall peptide identification efficiency, particularly for posttranslationally modified peptides of interest. Additionally, coupling targeted MS/MS with DREAMS technology $y^{\circ}\left[15,{ }^{\circ} 16\right]^{\circ}$ to $^{\circ}$ enable $^{\circ}$ characterization $^{\circ}$ of lower abundance species holds great potential for targeted analysis of clinical samples, for example, focusing on features exhibiting significant changes in abundances.

Table 1. Summary ${ }^{\circ}$ of $^{\circ} \mathrm{ICR}-2 \mathrm{LS}^{\circ} \mathrm{MS} / \mathrm{MS}^{\circ}$ search $^{\circ}$ result $^{\circ}$ from ${ }^{\circ}$ Figure ${ }^{\circ} 7$

\begin{tabular}{|c|c|c|c|c|c|}
\hline Charge state & $m / z$ & $\begin{array}{c}\text { Monoisotopic } \\
\text { MW }\end{array}$ & Fragment & $\begin{array}{c}\text { Theoretical } \\
\text { MW }\end{array}$ & $\begin{array}{l}\mathrm{MMA}^{\mathrm{a}} \\
(\mathrm{ppm})\end{array}$ \\
\hline 2 & 406.243 & 810.470 & y7 & 810.471 & -0.98 \\
\hline 1 & 433.241 & 432.233 & y4 & 432.233 & 0.11 \\
\hline 1 & 444.209 & 443.202 & b4 & 443.202 & -0.03 \\
\hline 2 & 470.763 & 939.512 & y8 & 939.514 & -2.22 \\
\hline 2 & 490.743 & 979.471 & b9 & 979.472 & -1.02 \\
\hline 2 & 506.282 & 1010.550 & y9 & 1010.550 & -0.85 \\
\hline 1 & 546.324 & 545.317 & y5 & 545.317 & -0.52 \\
\hline 2 & 563.795 & 1125.580 & DAEKHLTNAK & 1125.58 & -1.35 \\
\hline 1 & 683.382 & 682.375 & y6 & 682.376 & -1.59 \\
\hline 1 & 694.351 & 693.344 & b6 & 693.345 & -1.06 \\
\hline 1 & 795.398 & 794.390 & b7 & 794.392 & -2.31 \\
\hline 1 & 811.477 & 810.469 & y7 & 810.471 & -2.32 \\
\hline 1 & 909.445 & 908.438 & b8 & 908.435 & 2.55 \\
\hline 1 & 980.477 & 979.469 & b9 & 979.472 & -2.87 \\
\hline
\end{tabular}

aMass measurement accuracy (difference between measured and theoretical molecular mass divided by theoretical molecular mass). 


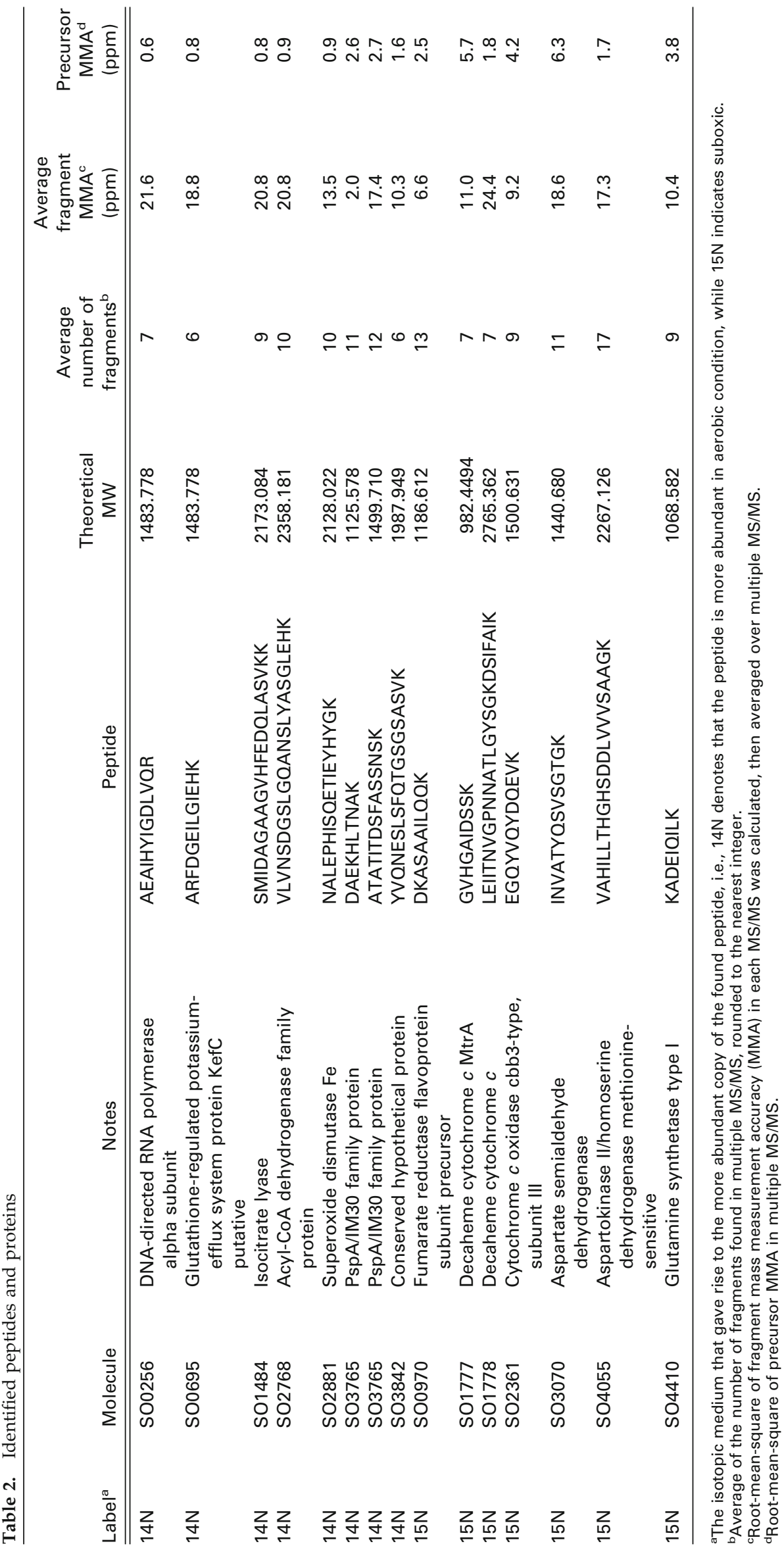




\section{Conclusions}

In this study, an existing hardware platform for external ion selection and dissociation was modified and optimized for targeted LC-MS/MS applications. Novel software for on-the-fly correction of the LC elution time shifts was also developed and successfully applied. By targeting solely peptides of interest, we were able to identify a subset of differentially abundant peptides/ proteins for S. oneidensis grown under aerobic versus suboxic conditions. External ion selection and dissociation increased the overall efficiency of targeted MS/MS analysis ${ }^{\circ}$ in $^{\circ}$ comparison $^{\circ}$ to $^{\circ}$ our $^{\circ}$ earlier ${ }^{\circ}$ study ${ }^{\circ}[6]^{\circ},{ }^{\circ}$ which employed in-trap ion selection and dissociation (SWIFT-SORI-CID).

\section{Acknowledgments}

The authors thank Michael A. Buschbach for programming support; Nikola Tolić for assistance with data analysis; Navdeep Jaitly for helpful discussion; David C. Prior and Andrey N. Vilkov for their help with instrumentation; Gregory Pinchuk, Jeff McLean, and Yuri Gorby for growing the $S$. oneidensis cells. Portions of this research were supported by the office of Biological and Environmental Research, U.S. Department of Energy; the National Cancer Institute under grants CA81654 and CA86340; and the National Center for Research Resources (RR18522). Pacific Northwest National Laboratory is operated by Battelle Memorial Institute for the U.S. Department of Energy under contract DE-AC05-76RLO 1830.

\section{References}

1. Davis, M. T.; Stahl, D. C.; Hefta, S. A.; Lee, T. D. A Microscale Electrospray Interface for Online, Capillary Liquid-Chromatography Tandem Mass-Spectrometry of Complex Peptide Mixtures. Anal. Chem. 1995, 67(24), 4549-4556.

2. Davis, M. T.; Lee, T. D. Variable Flow Liquid Chromatography Tandem Mass Spectrometry and the Comprehensive Analysis of Complex Protein Digest Mixtures. J. Am. Soc. Mass Spectrom. 1997, 8(10), 1059 1069.

3. Davis, M. T.; Spahr, C. S.; McGinley, M. D.; Robinson, J. H.; Bures, E. J.; Beierle, J.; Mort, J.; Yu, W.; Luethy, R.; Patterson, S. D. Towards Defining the Urinary Proteome Using Liquid Chromatography-Tandem Mass Spectrometry. II. Limitations of Complex Mixture Analyses. Proteomics 2001, 1(1), 108-117.

4. Masselon, C.; Anderson, G. A.; Harkewicz, R.; Bruce, J. E.; Paša-Tolić, L.; Smith, R. D. Accurate Mass Multiplexed Tandem Mass Spectrometry for High-Throughput Polypeptide Identification from Mixtures. Anal. Chem. 2000, 72(8), 1918-1924.

5. Shen, Y. F.; Zhao, R.; Belov, M. E.; Conrads, T. P.; Anderson, G. A.; Tang, K. Q.; Paša-Tolić, L.; Veenstra, T. D.; Lipton, M. S.; Udseth, H. R.; Smith, R. D. Packed Capillary Reversed-Phase Liquid Chromatography with High-Performance Electrospray Ionization Fourier Transform Ion Cyclotron Resonance Mass Spectrometry for Proteomics. Anal. Chem. 2001, 73(8), 1766-1775.

6. Masselon, C.; Paša-Tolić, L.; Tolić, N.; Anderson, G. A.; Bogdanov, B.; Vilkov, A. N.; Shen, Y. F.; Zhao, R.; Oian, W. J.; Lipton, M. S.; Camp, D. G.; Smith, R. D. Targeted Comparative Proteomics by Liquid Chromatography-Tandem Fourier Ion Cyclotron Resonance Mass Spectrometry. Anal. Chem. 2005, 77(2), 400-406.

7. Giometti, C. S.; Khare, T.; Tollaksen, S. L.; Tsapin, A.; Zhu, W. H.; Yates, J. R.; Nealson, K. H. Analysis of the Shewanella oneidensis Proteome by Two-Dimensional Gel Electrophoresis Under Three Nondenaturing Conditions. Proteomics 2003, 3(5), 777-785.

8. Marshall, A. G.; Wang, T. C. L.; Ricca, T. L. Tailored Excitation for Fourier-Transform Ion-Cyclotron Resonance Mass-Spectrometry. J. Am. Chem. Soc. 1985, 107(26), 7893-7897.

9. Gauthier, J. W.; Trautman, T. R.; Jacobson, D. B. Sustained OffResonance Irradiation for Collision-Activated Dissociation Involving Fourier-Transform Mass-Spectrometry-Collision-Activated Dissociation Technique That Emulates Infrared Multiphoton Dissociation. Anal. Chim. Acta 1991, 246(1), 211-225.

10. Vilkov, A. N.; Bogdanov, B.; Paša-Tolić, L.; Prior, D. C.; Anderson, G. A.; Masselon, C. D.; Moore, R. J.; Smith, R. D. Tailored Noise Waveform/
Collision-Induced Dissociation of Ions Stored in a Linear Ion Trap Combined with Liquid Chromatography/Fournier Transform Ion Cyclotron Resonance Mass Spectrometry. Rapid Commun. Mass Spectrom. 2004, 18(22), 2682-2690.

11. Shen, Y. F.; Moore, R. J.; Zhao, R.; Blonder, J.; Auberry, D. L.; Masselon, C.; Paša-Tolić, L.; Hixson, K. K.; Auberry, K. J.; Smith, R. D. HighEfficiency On-Line Solid-Phase Extraction Coupling to 15 to $150-\mu \mathrm{m}$ i.d. Column Liquid Chromatography for Proteomic Analysis. Anal. Chem. 2003, 75(14), 3596-3605.

12. Kelly, R. T.; Page, J. S.; Luo, Q.; Moore, R. J.; Orton, D. J.; Tang, K.; Smith, R. D. Chemically Etched Open Tubular and Monolithic Emitters for Nanoelectrospray Ionization Mass Spectrometry. Anal. Chem. 2006, 78(22), 7796-7801.

13. Shaffer, S. A.; Tang, K. Q.; Anderson, G. A.; Prior, D. C.; Udseth, H. R.; Smith, R. D. A Novel Ion Funnel for Focusing Ions at Elevated Pressure Using Electrospray Ionization Mass Spectrometry. Rapid Commun. Mass Spectrom. 1997, 11(16), 1813-1817.

14. Beu, S. C.; Laude, D. A. Open Trapped Ion Cell Geometries for Fourier-Transform Ion-Cyclotron Resonance Mass-Spectrometry. Int. J. Mass Spectrom. Ion Processes 1992, 112(2/3), 215-230.

15. Belov, M. E.; Anderson, G. A.; Angell, N. H.; Shen, Y. F.; Tolić, N. Udseth, H. R.; Smith, R. D. Dynamic Range Expansion Applied to Mass Spectrometry Based on Data-Dependent Selective Ion Ejection in Capillary Liquid Chromatography Fourier Transform Ion Cyclotron Resonance for Enhanced Proteome Characterization. Anal. Chem. 2001, 73(21), 5052-5060.

16. Harkewicz, R.; Belov, M. E.; Anderson, G. A.; Paša-Tolić, L.; Masselon, C. D.; Prior, D. C.; Udseth, H. R.; Smith, R. D. ESI-FTICR Mass Spectrometry Employing Data-Dependent External Ion Selection and Accumulation. J. Am. Soc. Mass Spectrom. 2002, 13(2), 144-154.

17. Louris, J. N.; Cooks, R. G.; Syka, J. E. P.; Kelley, P. E.; Stafford, G. C.; Todd, J. F. J. Instrumentation, Applications, and Energy Deposition in Quadrupole Ion-Trap Tandem Mass-Spectrometry. Anal. Chem. 1987, 59(13), 1677-1685.

18. Patrie, S. M.; Charlebois, J. P.; Whipple, D.; Kelleher, N. L.; Hendrickson, C. L.; Quinn, J. P.; Marshall, A. G.; Mukhopadhyay, B. Construction of a Hybrid Quadrupole/Fourier Transform Ion Cyclotron Resonance Mass Spectrometer for Versatile MS/MS Above $10 \mathrm{kDa}$. J. Am. Soc. Mass Spectrom. 2004, 15(7), 1099-1108.

19. Jebanathirajah, J. A.; Pittman, J. L.; Thomson, B. A.; Budnik, B. A.; Kaur, P.; Rape, M.; Kirschner, M.; Costello, C. E.; O'Connor, P. B. Characterization of a New qQq-FTICR Mass Spectrometer for Post-Translational Modification Analysis and Top-Down Tandem Mass Spectrometry of Whole Proteins. J. Am. Soc. Mass Spectrom. 2005, 16(12), 1985-1999.

20. Tolmachev, A. V.; Vilkov, A. N.; Bogdanov, B.; Paša-Tolić, L.; Masselon, C. D.; Smith, R. D. Collisional Activation of Ions in rf Ion Traps and Ion Guides: The Effective Ion Temperature Treatment. J. Am. Soc. Mass Spectrom. 2004, 15(11), 1616-1628.

21. Kiebel, G. R.; Auberry, K. J.; Jaitly, N.; Clark, D. A.; Monroe, M. E.; Peterson, E. S.; Tolić, N.; Anderson, G. A.; Smith, R. D. PRISM: A Data Management System for High-Throughput Proteomics. Proteomics 2006, 6(6), 1783-1790.

22. Zimmer, J. S.; Monroe, M. E.; Qian, W. J.; Smith, R. D. Advances in Proteomics Data Analysis and Display Using an Accurate Mass and Time Tag Approach. Mass Spectrom. Rev. 2006, 25(3), 450-82.

23. Jaitly, N.; Monroe, M. E.; Petyuk, V. A.; Clauss, T. R. W.; Adkins, J. N.; Smith, R. D. Robust Algorithm for Alignment of Liquid Chromatography-Mass Spectrometry Analyses in an Accurate Mass and Time Tag Data Analysis Pipeline. Anal. Chem. 2006, 78(21), 7397-7409.

24. van der Burgt, Y. E. M.; Taban, I. M.; Konijnenburg, M.; Biskup, M.; Duursma, M. C.; Heeren, R. M. A.; Rompp, A.; van Nieuwpoort, R. V.; Bal, H. E. Parallel Processing of Large Datasets from NanoLCFTICR-MS Measurements. J. Am. Soc. Mass Spectrom. 2007, 18(1), 152 161

25. Dawson, P. H. Acceptance of Quadrupole Mass Filter. Int. J. Mass Spectrom. Ion Processes 1975, 17(4), 423-445.

26. Horn, D. M.; Zubarev, R. A.; McLafferty, F. W. Automated Reduction and Interpretation of High Resolution Electrospray Mass Spectra of Large Molecules. J. Am. Soc. Mass Spectrom. 2000, 11(4), 320-332.

27. Haller, I.; Mirza, U. A.; Chait, B. T. Collision Induced Decomposition of Peptides. Choice of Collision Parameters. J. Am. Soc. Mass Spectrom. 1996, 7(7), 677-681.

28. Tolmachev, A. V.; Monroe, M. E.; Jaitly, N.; Petyuk, V. A.; Adkins, J. N.; Smith, R. D. Mass Measurement Accuracy in Analyses of Highly Complex Mixtures Based Upon Multidimensional Recalibration. Anal. Chem. 2006, 78(24), 8374-8385.

29. Perkins, D. N.; Pappin, D. J. C.; Creasy, D. M.; Cottrell, J. S. Probability-Based Protein Identification by Searching Sequence $\mathrm{Da}$ tabases Using Mass Spectrometry data. Electrophoresis 1999, 20(18), 3551-3567.

30. Kolker, E.; Picone, A. F.; Galperin, M. Y.; Romine, M. F.; Higdon, R.; Makarova, K. S.; Kolker, N.; Anderson, G. A.; Qiu, X. Y.; Auberry, K. J.; Babnigg, G.; Beliaev, A. S.; Edlefsen, P.; Elias, D. A.; Gorby, Y. A.; Holzman, T.; Klappenbach, J. A.; Konstantinidis, K. T.; Land, M. L.; Lipton, M. S.; McCue, L. A.; Monroe, M.; Paša-Tolić, L.; Pinchuk, G.; Purvine, S.; Serres, M. H.; Tsapin, S.; Zakrajsek, B. A.; Zhou, J. H.; Larimer, F. W.; Lawrence, C. E.; Riley, M.; Collart, F. R.; Yates, J. R.; Smith, R. D.; Giometti, C. S.; Nealson, K. H.; Fredrickson, J. K.; Tiedje, J. M. Global profiling of Shewanella oneidensis MR-1: Expression of 
Hypothetical Genes and Improved Functional Annotations. Proc. Natl. Acad. Sci. U.S.A. 2005, 102(6), 2099-2104.

31. Fang, R. H.; Elias, D. A.; Monroe, M. E.; Shen, Y. F.; McIntosh, M.; Wang, P.; Goddard, C. D.; Callister, S. J.; Moore, R. J.; Gorby, Y. A.; Adkins, J. N.; Fredrickson, J. K.; Lipton, M. S.; Smith, R. D. Differential Label-Free Quantitative Proteomic Analysis of Shewanella oneidensis Cultured Under Aerobic and Suboxic Conditions by Accurate Mass and Time Tag Approach. Mol. Cell. Proteom. 2006, 5(4), 714-725.
32. Zubarev, R. A.; Kelleher, N. L.; McLafferty, F. W. Electron Capture Dissociation of Multiply Charged Protein Cations. A Nonergodic Process. J. Am. Chem. Soc. 1998, 120(13), 3265-3266.

33. Zubarev, R. A., Electron-Capture Dissociation Tandem Mass Spectrometry. Curr. Opin. Biotechnol. 2004, 15(1), 12-16.

34. Zubarev, R. Protein Primary Structure Using Orthogonal Fragmentation Techniques in Fourier Transform Mass Spectrometry. Expert Rev. Proteom. 2006, 3(2), 251-261. 